\title{
Pengaruh Penerapan Model Pembelajaran Open Ended Problem pada Mata Kuliah Kalkulus di STMIK Lamappoleonro
}

\author{
Misveria Villa Waru \\ Sistem Informasi, STMIK Lamappapoleonro Soppeng \\ veriawaru@gmail.com
}

\begin{abstract}
ABSTRAK
Penelitian ini bertujuan untuk mengetahui pengaruh penerapan model pembelajaran open ended problem terhadap hasil belajar mahasiswa pada mata kuliah Kalkulus di STIMIK Lamappoleonro. Jenis penelitian ini adalah penelitian ekperimen semu (Quasi Eksperimen) dengan Teknik pengumpulan data menggunakan tes dalam bentuk one group Pretest - posttest design dengan teknik random sampling. Subyek penelitian ini yaitu mahasiswa program studi teknik informatika yang sedang menempuh mata kuliah Kalkulus pada semester genap tahun akademik 2018/2019. Hasil penelitian diperoleh rata-rata hasil belajar pretest 50,13 dan posttest 84 . Berdasarkan hasil pengujian hipotesis dengan menggunakan uji t berpasangan diperoleh nilai t 27,13 dan sig. 0,0001 karena nilai sig lebih kecil dari $5 \%$ maka penerapan dengan model pembelajaran open ended problem dapat meningkatkan hasil belajar mahasiswa pada mata kuliah kalkulus di STIMIK Lamappoleonro.
\end{abstract}

Kata Kunci: Model Open Ended Problem, Hasil Belajar, Kalkulus.

\begin{abstract}
This study aims to determine the effect of the application of the open-ended problem learning model on student learning outcomes in the calculus course at STIMIK Lamappoleonro. This type of research is quasi-experimental research (Quasi Experiment) using one group pre-test-posttest design with random sampling technique. The subjects of this study were students of the informatics engineering study program who were taking the Calculus course in the even semester of the 2018/2019 academic year. The results of the study obtained an average pre-test learning outcomes of 50.13 and 84 posttests. Based on the results of hypothesis testing using paired $t$ test, the $t$ value was 27.13 and sig. 0.0001 because the sig value is smaller than $5 \%$, the application of the open-ended problem learning model can improve student learning outcomes in calculus courses at STIMIK Lamappoleonro.
\end{abstract}

Keywords: Open Ended Problem model, Learning Achievement, Calculus.

\section{A. PENDAHULUAN}

Upaya dalam meningkatkan mutu pendidikan yaitu mengoptimalkan proses belajar mengajar, sehingga diperoleh hasil belajar sesuai dengan tujuan yang diharapkan. Serta adanya kesadaran diri mahasiswa dan dosen untuk terlibat secara aktif dalam proses belajar mengajar sangat dibutuhkan (Arsyad et al., 2017)

Pembelajaran tersebut juga harus mampu mengisi struktur kognitif mahasiswa dengan berbagai pengetahuan. Dalam hal ini pembelajaran hendaknya didesain dengan mengenengahkan peran aktif mahasiswa 
sebagai subjek pembelajaran untuk secara langsung mengkonstruksi pengetahuannya sendiri melalui berbagai kegiatan pembelajaran. Seorang dosen harus berusaha agar materi pembelajaran yang disampaikan mampu diserap/dimengerti dengan mudah oleh mahasiswa (Mursidik et al., 2015)

Permasalahan tersebut perlu segera dicari solusinya yakni bagaimana usaha yang tepat untuk perbaikan pengajaran pada mata kuliah Kalkulus, agar mahasiswa dapat dengan mudah menyerap dan memahaminya. Perlu dicari model pembelajaran yang tepat gagasangagasan dari pengalaman yang mereka alami yang berhubungan dengan materi yang mereka pelajari di kelas.

Salah satu upaya untuk meningkatkan mutu pendidikan dalam proses belajar mengajar yaitu dengan menerapkan model pembelajaran. Model pembelajaran merupakan seluruh rangkaian penyajian materi yang meliputi segala aspek sebelum, sedang dan sesudah pembelajaran yang dilakukan serta segala fasilitas yang terkait yang digunakan secara langsung atau tidak langsung dalam proses belajar mengajar (Lambertus et al., 2013) Model pembelajan sendiri memiliki makna yang lebih luas dari pada strategi, metode atau sekedar prosedur pembelajaran. Pada penelitian ini, digunakan model pembelajaran Open Ended Problem, dimana model pembelajaran Open Ended Problem adalah problem yang diformulasikan memiliki multi jawaban yang benar disebut problem tak lengkap atau disebut juga Open-Ended problem atau soal terbuka. Mahasiswa yang dihadapkan dengan OpenEnded problem, tujuan utamanya bukan untuk mendapatkan jawaban tetapi lebih menekankan pada cara bagaimana sampai pada suatu jawaban. Dengan demikian bukanlah hanya satu pendekatan atau metode dalam mendapatkan jawaban, namun beberapa atau banyak (Sulianto, 2011). Dengan diterapkannya model pembelajaran ini diharapkan mahasiswa mampu menyelesaikan masalah dengan melihat banyak aspek sebagai bahan pertimbangan serta alternatif jawaban yang dapat digunakan. Soal yang akan diberikan pada penelitian ini merupakan soal yang berdasarkan pada kehidupan sehari-harinya.

\section{Masalah Penelitian}

Apakah ada pengaruh penerapan model pembelajaran Open Ended Problem pada mata kuliah Kalkulus di STMIK Lamappoleonro?

\section{Fokus Penelitian}

Adapun Tujuan dalam penelitian ini yaitu untuk melihah pengaruh penerapan model pembelajaran Open Ended Problem pada mata kuliah Kalkulus di STMIK Lamappoleonro

\section{B. METODE}

Penelitian ini termasuk penelitian eksperimen semu (Quasi Eksperiment) yang bertujuan untuk mengetahui pengaruh model pembelajaran open ended problem terhadap hasil belajar pada mata kuliah Kalkulus. 
Subyek penelitian ini yaitu mahasiswa semester genap tahun akademik 2018/2019 yang sedang menempuh mata kuliah kalkulus.

Prosedur penelitian di bagi menjadi dua tahap, yaitu tahap persiapan dan tahap pelaksanaan, yaitu:

\section{Tahap Persiapan}

a. Menyusun skenario pembelajaran yang berisikan langkah-langkah pembelajaran dengan model pembelajaran Open Ended Problem

b. Merancang dan membuat instrument atau alat evaluasi sebagai informasi untuk mengukur kemampuan atau pemahaman mahasiswa setelah mengikuti pembelajaran berupa tes hasil belajar

\section{Tahap Pelaksanaan}

Kegiatan belajar mengajar dilaksanakan selama 10 jam pelajaran untuk kelas eksperimen.

Data hasil penelitian berupa skor hasil belajar kognitif, dianalisis dengan analisis deskriptif dan analisis inferensial. Analisis deskriftif digunakan untuk mendeskripsikan hasil belajar yang diperoleh mahasiswa. Analisis ini juga digunakan untuk mendeskripsikan hasil belajar mahasiswa setelah diterapkan model pembelajaran Open Ended Problem. Analisis Inferensial digunakan untuk menguji hipotesis analisis inferensial dengan menggunakan uji t paired sample t-tes. Rumus yang digunakan untuk menghitung nilai perolehan keterampilan metakognisi dan hasil belajar mahasiswa sebagai berikut:

$$
\text { Nilai }=\frac{\text { Skor Perolehan }}{\text { Skor Maksimal }} \times 100
$$

Dalam penelitian ini digunakan statistik deskriptif yaitu mean, median, modus, varians dan simpangan baku, yang bertujuan untuk melihat gambaran data yang diperoleh. Untuk statistik inferensialnya digunakan uji paired sample t-test. Dimana uji ini digunakan untuk menguji hipotesis dalam penelitian ini. Ada pun rumusnya sebagai berikut:

$$
t=\frac{b}{s_{b / \sqrt{n}}}
$$

Dimana:

$\mathrm{t}=$ Nilai $\mathrm{t}$ hitung

$\mathrm{b}=$ selisih antara post-test dan pre-test

$\mathrm{s}_{\mathrm{b}}=$ Simpangan baku dari selisih antara posttest dan pre-test dst.

\section{HASIL DAN PEMBAHASAN}

\section{Hasil Belajar sebelum diterapkan Model Pembelajaran Open Ended Problem}

Berdasarkan nilai hasil belajar dari 30 orang mahasiswa dengan menggunakan model pembelajaran Open Ended Problem diperoleh nilai rata-rata yaitu 50,13 nilai maksimum yaitu 60 , nilai minimum yaitu 40 , nilai modus yaitu 48 , nilai median yaitu 48. Berdasarkan hasil belajar 
mahasiswa tersebut diatas dapat dikategorikan seperti tabel 1:

Tabel 1. Kategori Hasil Belajar sebelum penerapan model pembelajaran Open Ended Problem

\begin{tabular}{cclcc}
\hline No & Interval & Kategori & $\mathbf{f}$ & $\mathbf{\%}$ \\
\hline 1 & $85-100$ & Sangat Tinggi & 0 & $0 \%$ \\
\hline 2 & $65-84$ & Tinggi & 0 & $0 \%$ \\
\hline 3 & $55-64$ & Sedang & 7 & $23 \%$ \\
\hline 4 & $35-54$ & Rendah & 23 & $77 \%$ \\
\hline 5 & $0-34$ & Sangat Rendah & 0 & $0 \%$ \\
\hline \multicolumn{5}{c}{ Total } \\
\hline
\end{tabular}

Berdasarkan tabel 1 diatas dapat dilihat bahwa, untuk skor 85-100 termasuk dalam kategori sangat tinggi frekuensi tidak ada. Untuk skor 6584 yang termasuk dalam kategori tinggi frekuensi tidak ada. Untuk skor 55-64 termasuk dalam kategori sedang frekuensi yang dicapai adalah 7 dari 30 orang mahasiswa dengan persentase $23 \%$. Untuk skor 35-54 termasuk dalam kategori rendah frekuensi yang dicapai adalah 23 dari 30 dengan presentase $77 \%$. Sedangkan untuk skor 0-34 termasuk dalam kategori sangat rendah frekuensi tidak ada.

\section{Hasil Belajar sesudah penerapan model Pembelajaran Open Ended Problem}

Berdasarkan nilai hasil belajar dari 30 orang mahasiswa dengan menggunakan model pembelajaran Open Ended Problem diperoleh nilai rata-rata yaitu 84 nilai maksimum yaitu 92 , nilai minimum yaitu 76 , nilai modus yaitu 80 , nilai median yaitu 84. Berdasarkan hasil belajar mahasiswa tersebut diatas dapat dikategorikan seperti tabel 2 .

Tabel 2. Kategori Hasil Belajar sesudah penerapan model pembelajaran Open Ended Problem

\begin{tabular}{cclcc}
\hline No & Interval & Kategori & $\mathbf{f}$ & $\%$ \\
\hline 1 & $85-100$ & Sangat Tinggi & 11 & $37 \%$ \\
\hline 2 & $65-84$ & Tinggi & 19 & $63 \%$ \\
\hline 3 & $55-64$ & Sedang & 0 & $0 \%$ \\
\hline 4 & $35-54$ & Rendah & 0 & $0 \%$ \\
\hline 5 & $0-34$ & Sangat Rendah & 0 & $0 \%$ \\
\hline \multicolumn{5}{c}{ Total } \\
\hline
\end{tabular}

Berdasarkan tabel 2 diatas dapat dilihat bahwa, untuk skor 85-100 termasuk dalam kategori sangat tinggi frekuensi sebanyak 11 mahasiswa dari 30 mahasiswa dengan presentase 37\%. Untuk skor 65-84 yang termasuk dalam kategori baik frekuensi sebanyak 19 mahasiswa dari 30 mahasiswa dengan presentase 63\%. Untuk skor 55-64 termasuk dalam kategori sedang frekuensi tidak ada. Untuk skor 35-54 termasuk dalam kategori rendah frekuensi tidak ada. Sedangkan untuk skor 0-34 termasuk dalam kategori sangat rendah frekuensi tidak ada.

\section{Pengujian Hipotesis}

Data dianalisis dengan Uji Independent $T$ Test, tetapi sebelumnya diuji prasyarat yaitu uji normalitas dengan uji statistik One Sample Kolmogorov-Smirnov Test dan uji homegenitas digunakan uji statistik Leven's Test of Equality of Error Variances. Jika hasil uji normalitas dan homogenitas, data berdistribusi normal dan varians antara kelompok homogen maka dapat 
dilanjutkan uji statistik dengan menggunakan statistik parametris yaitu Uji Independent T Test.

Hipotesis statistik: $\mathrm{H}_{0}: \mu_{1}=\mu_{2}$, artinya tidak ada perbedaan hasil belajar mahasiswa sebelum dan sesudah diterapkan model pembelajaran Open Ended Problem pada mata kuliah kalkulus. $\mathrm{H}_{1}: \mu_{1} \neq \mu_{2}$, artinya terdapat perbedaan hasil belajar mahasiswa sebelum dan sesudah diterapkan model pembelajaran Open Ended Problem pada mata kuliah kalkulus. Kriteria pengujiannya: $H_{0}$ diterima, jika $\rho \geq \alpha(0,05)$ $H_{0}$ ditolak, jika $\rho<\alpha(0,05)$

\section{a. Hasil Uji Prasyarat Analisis (Uji Asumsi)}

Uji prasyarat analisis yang digunakan adalah menguji normalitas sebaran data. Uji normalitas sebaran data digunakan uji statistik One Sample Kolmogorov-Smirnov Test.

Hasil uji normalitas data kesadaran metakognisi mahasiswa disajikan pada tabel 3 dan hasil uji normalitas data secara lengkap disajikan pada Lampiran.

Tabel 3. Hasil Uji Normalitas nilai N-Gain model pembelajaran self regulated learning dan model pembelajaran Open Ended Problem

\begin{tabular}{c|c|c|c}
\hline \multicolumn{4}{c}{ Kolmogorov-Smirnov $^{\mathbf{a}}$} \\
\hline $\begin{array}{c}\text { Nilai } \\
\text { N-Gain }\end{array}$ & $\begin{array}{c}\text { Kolmogorov } \\
\text { Smirnov }\end{array}$ & $\begin{array}{c}\text { Alpha } \\
(\boldsymbol{\alpha})\end{array}$ & $\begin{array}{c}\text { Sig. } \\
\text { (2-tailed) }\end{array}$ \\
\hline Pre Test & 0,923 & 0,05 & 0,362 \\
\hline Post Test & 1,104 & 0,05 & 0,175 \\
\hline
\end{tabular}

Berdasarkan hasil uji normalitas pada Tabel 3 diperoleh nilai signifikansi ( $\rho$ ) pretest dan posttest $(0,362$ dan 0,175$)$ lebih besar dari alpha $5 \%(\rho=0,362,0,175>\alpha=0,05)$. Hal ini berarti $\mathrm{H}_{0}$ diterima dan $\mathrm{H}_{1}$ ditolak. jadi data pretest dan posttest berdistribusi normal.

\section{b. Hasil Uji Hipotesis}

Untuk menguji hipotesis pengaruh model pembelajaran terhadap hasil belajar mahasiswa digunakan uji statistik paired sample $t$ test. Interpretasi adanya perbedaan hasil belajar mahasiswa sebelum dan sesudah diterapkan model pembelajaran Open Ended Problem pada mata kuliah kalkulus dapat diketahui dengan membandingkan nilai signifikansi (sig 2tailed) yang diperoleh dari hasil uji dengan nilai alpha $5 \%(0,05)$. Hasil ringkasan uji disajikan pada Tabel 4.

Tabel 4. Hasil Uji Perbedaan (uji-t) Nilai N-Gain hasil belajar mahasiswa self regulated learning dan Open Ended Problem

\begin{tabular}{c|c|c|c}
\hline \multicolumn{4}{c}{ Paired Samples t-Test } \\
\hline & Nilai t & $\begin{array}{c}\text { Alpha } \\
(\boldsymbol{\alpha})\end{array}$ & $\begin{array}{c}\text { Sig. } \\
(\text { 2-tailed) }\end{array}$ \\
\hline $\begin{array}{c}\text { Nilai Pre Test } \\
\text { dan Post Test }\end{array}$ & 27,013 & 0,05 & 0,0001 \\
\hline
\end{tabular}

Berdasarkan hasil uji perbedaan (uji-t) data nilai $\mathrm{N}$-gain pada Tabel 4. diperoleh nilai signifikansi $(\rho)$ nilai $\mathrm{N}$-Gain lebih kecil dari alpha $(\alpha) 5 \%,(\rho=0,025>\alpha=0,05)$. Hal ini berarti bahwa hipoptesis statistik $\mathrm{H}_{1}$ yang menyatakan bahwa "terdapat perbedaan hasil belajar mahasiswa sebelum dan sesudah diterapkan model pembelajaran Open Ended Problem pada mata kuliah kalkulus" diterima dan $\mathrm{H}_{0}$ ditolak. Jadi dapat dikatakan bahwa dengan penerapan model pembelajaran Open Ended Problem mampu 
meningkatkan hasil belajar mahasiswa pada mata kuliah kalkulus.

\section{Pembahasan}

Penggunaan model pembelajaran Open Ended Problem dengan menggunakan metode demonstrasi memberikan pengaruh terhadap hasil belajar mata kuliah kalkulus. Pengaruh tersebut antara lain dalam penggunaan model pembelajaran Open Ended Problem dengan menggunakan metode demonstrasi peserta didik harus mempertanggung-jawabkan hasil diskusi mereka bersama kelompok ahli kepada kelompok asal. Ketika mempresentasikan hasil diskusi tidak dengan sikap yang tanggung jawab dan percaya diri, maka akan memberikan hasil yang tidak maksimal untuk pemahaman kepada kelompok asal terhadap materi pembelajaran tersebut. Pembelajaran dengan menggunakan model pembelajaran Open Ended Problem dengan menggunakan metode demonstrasi dapat membantu mahasiswa meningkatkan pengetahuan, pemahaman, dan penerapan mahasiswa terhadap konsep mahasiswa yang dipelajari. Peningkatan ini terjadi dikarenakan mahasiswa secara langsung mencari dan memahami konsep serta menjelaskan kembali pada teman-teman satu kelompoknya, baik kelompok asal maupun kelompok ahli.

Secara keseluruhan perolehan nilai rata-rata yang hampir sama pre test yaitu 50,13 untuk post test, 84. Dari hasil observasi model pembelajaran tipe Open Ended Problem dengan menggunakan metode demonstrasi mempunyai peranan lebih dalam meningkatkan hasil belajar mata kuliah kalkulus, hal tersebut ditunjukkan dengan adanya peningkatan pada masingmasing aspek di setiap pertemuan. Aspek-aspek tersebut diantaranya yaitu :

a. berpartisipasi antar anggota kelompok,

b. keaktifan dalam kerja kelompok,

c. mampu bertanggungjawab dalam menjelaskan materi dan

d. bekerja sama dengan baik antar sesama anggota kelompok.

Dari hasil observasi tersebut sesuai dengan pendapat (Sari et al., 2016) menyatakan bahwa kelebihan model pembelajaran Open Ended Problem yaitu:

a. Peserta didik dilibatkan pada kegiatan belajar sehingga pengetahuannya benar-benar diserap dengan baik,

b. Dilatih untuk mandiri dan bekerja sama dengan peserta didik lain,

c. Berperan aktif dan menuntut keterampilan berfikir peserta didik yang lebih tinggi dalam pembelajaran.

d. Peserta didik dapat merasakan manfaat pembelajaran matematika sebab masalah yang diselesaikan merupakan masalah sehari-hari.

e. Dapat mengembangkan cara berfikir logis serta berlatih mengemukakan pendapat. 


\section{PENUTUP}

\section{Kesimpulan}

Berdasarkan hasil penelitian dan pembahasaan diatas, maka dapat disimpulkan bahwa :

a. Model Pembelajaran Open Ended Problem dengan metode demonstrasi efektif dalam meningkatkan hasil belajar Kalkulus berdasarkan nilai rata-rata pretest 50,13 meningkat pada posttest 84 .

b. Ada pengaruh penerapan model pembelajaran Open Ended Problem dengan metode demonstrasi pada pembelajaran mata kuliah kalkulus terhadap hasil belajar mahasiswa pada mata kuliah kalkulus di STMIK Lamappapoleonro Soppeng.

\section{Saran}

Berdasarkan kesimpulan di atas maka disarankan perlu adanya penerapan model pembelajaran lain pada mata kuliah lain dan disesuaikan terhadap karakter mata kuliah.

Kepada Kemenristek Dikti yang telah memberikan dana hibah untuk penelitian ini. Kepada pimpinan STIMIK Lamappoleonro yang telah memberikan izin untuk melaksanakan penelitian.

\section{DAFTAR PUSTAKA}

Arsyad, N., Rahman, A., \& Ahmar, A. S. (2017). Developing a self-learning model based on open-ended questions to increase the students' creativity in calculus. Global
Journal of Engineering Education, 19(2), 143-147.

https://doi.org/10.26858/gjeev19i2y2017 p143147

Lambertus, Arapu, L., \& Patih, T. (2013). Penerapan Pendekatan Open-Ended untuk Meningkatkan Kemampuan Berpikir Kreatif Matematik Siswa SMP. Pendidikan Matematika, 4(1), 73-82.

Mursidik, E. M., Samsiyah, N., \& Rudyanto, H. E. (2015). Creative Thinking Ability in Solving Open-Ended Mathematical Problems Viewed From the Level of Mathematics Ability of Elementary School Students. PEDAGOGIA: Journal of Education, 4(1), 23-33.

Sari, A. N., Wahyuni, R., \& Rosmaiyadi, R. (2016). Penerapan Pendekatan Open-Ended untuk Meningkatkan Kemampuan Berpikir Kritis Siswa Pada Materi Aljabar Kelas VIII SMP Negeri 10 Pemangkat. JPMI (Jurnal Pendidikan Matematika Indonesia), 1(1), 20. https://doi.org/10.26737/jpmi.v1i1.78

Sulianto, J. (2011). Keefektifan Model Pembelajaran Kontekstual Dengan Pendekatan Open Ended Dalam Pemecahan Masalah. Jurnal IImu Pendidikan Universitas Negeri Malang, 17(6).

\section{Ucapan Terima Kasih}

Ucapan terima kasih kepada seluruh yang mendukung penelitian ini, kepada ketua STMIK Lamappapoleonro atas dukungan dan motivasinya sehingga penelitian ini bisa selesai, kepada subjek penelitian yaitu mahasiswa STIMIK Lamappoleonro tahun ajaran 2018/2019, 